\title{
The opium poppy in Europe: exploring its origin and dispersal during the Neolithic
}

Aurélie Salavert ${ }^{1, *}$, Lucie Martin ${ }^{2}$, Ferran Antolín $^{3} \&$ Antoine Zazzo ${ }^{1}$

A new project aims to define the origins and dispersal patterns of the opium poppy in Neolithic Western Europe through a comprehensive programme of radiocarbon dating.

\section{Introduction}

The opium poppy (Papaver somniferum L.) has been of economic, therapeutic and symbolic importance for thousands of years, as evidenced by reference to opium production in fourthmillennium BC Sumerian clay tablets (Kritikos \& Papadaki 1967). In the absence of historical sources, archaeological seeds (and, only rarely, capsules and stigmatic disks) constitute the most direct and reliable evidence of the presence, use and cultivation of opium poppies in the past (Figure 1).

It is hypothesised that opium poppies were originally cultivated in the Mediterranean basin from the middle of the sixth millennium BC, where its putative wild ancestorPapaver somniferum subsp. setigerum — developed (Hammer \& Fritsch 1979; Schultze-Motel 1979). To date, however, the most frequent discoveries of Papaver somniferum beyond the Mediterranean region are from Linear Pottery Culture sites (5300-4900 BC); it thus followed a dispersal pattern from south to north (Bakels 1996; Salavert 2011) (Figure 2). The opium poppy is found in the Alpine region by the beginning of the fifth millennium BC (Martin 2015). This distribution raises the question of the diffusion process and the status of the plant. Why was it so rapidly adopted by Early Neolithic farmers in the north of continental Europe and the Alps at the end of the sixth millennium BC? Opium poppies do not seem to have followed the same dispersal trajectories as the cereals and pulses that accompanied the first farmers from the Near East to Western Europe, where the earliest finds of poppies, dating from 5300 BC onwards, are concentrated (Salavert 2010, 2017; Antolín et al. 2015). The opium poppy, therefore, may be the only plant whose domestication process began in Neolithic Europe.

1 Archéozoologie, Archéobotanique: Sociétés, Pratiques et Environnements (AASPE), Muséum National d'Histoire Naturelle, 57 Rue Cuvier, Paris, France

2 Université de Genève, Laboratoire D'archéologie Préhistorique et Anthropologie, 66, Boulevard Carl-Vogt, 1211 Genève 4, Switzerland

3 University of Basel, Integrative Prehistory and Archaeological Science (IPAS), Department of Environmental Sciences, Petersplatz 1, P.O. Box 4001 Basel, Switzerland

* Author for correspondence (Email: salavert@mnhn.fr)

(C) Antiquity Publications Ltd, 2018

ANTIQUITY 92 364, e1 (2018): 1-5

https://doi.org/10.15184/aqy.2018.154 


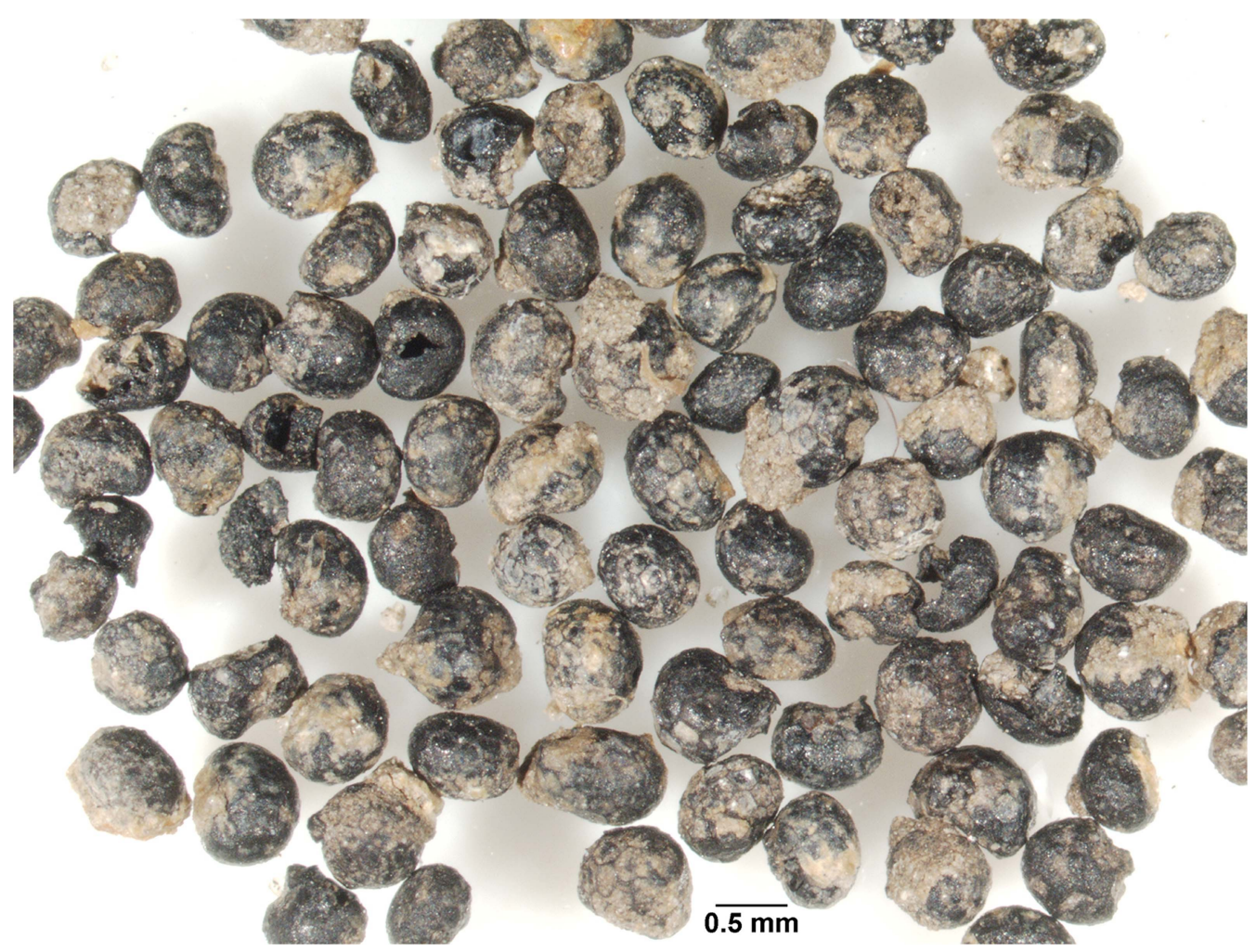

Figure 1. Charred Early Neolithic Papaver somniferum seeds from Buchères, France (photograph: F. Toulemonde).

Several obstacles currently prevent us from progressing the study of ancient poppy cultivation. The chronological framework covering the origins and distribution of the opium poppy is somewhat imprecise, being based on indirect and low-resolution dates. In addition, the native distribution area and the wild ancestor of the cultivated opium poppy are not identified with certainty; this strongly limits the hypotheses about the location of its early cultivation. Furthermore, the first uses and socio-economic status of the plant have been difficult to define due to their sparse representation in the archaeological record.

\section{Aims of the project and methodology}

This one-year project aims to reveal the origin of the opium poppy as a cultivar, and its spread across other regions, by providing a solid chronological framework. We will perform AMS dating of seeds from annual plants recovered from the same sieves as poppy seeds at approximately 40 Neolithic reference sites. Poppy seeds will also be directly dated, although

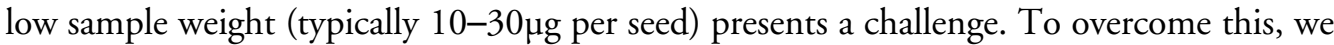
will use the mini radiocarbon dating system installed at Gif-sur-Yvette in France (ECHoMICADAS), which allows for analysis of very small samples (Figure 3). The results will then

(C) Antiquity Publications Ltd, 2018 


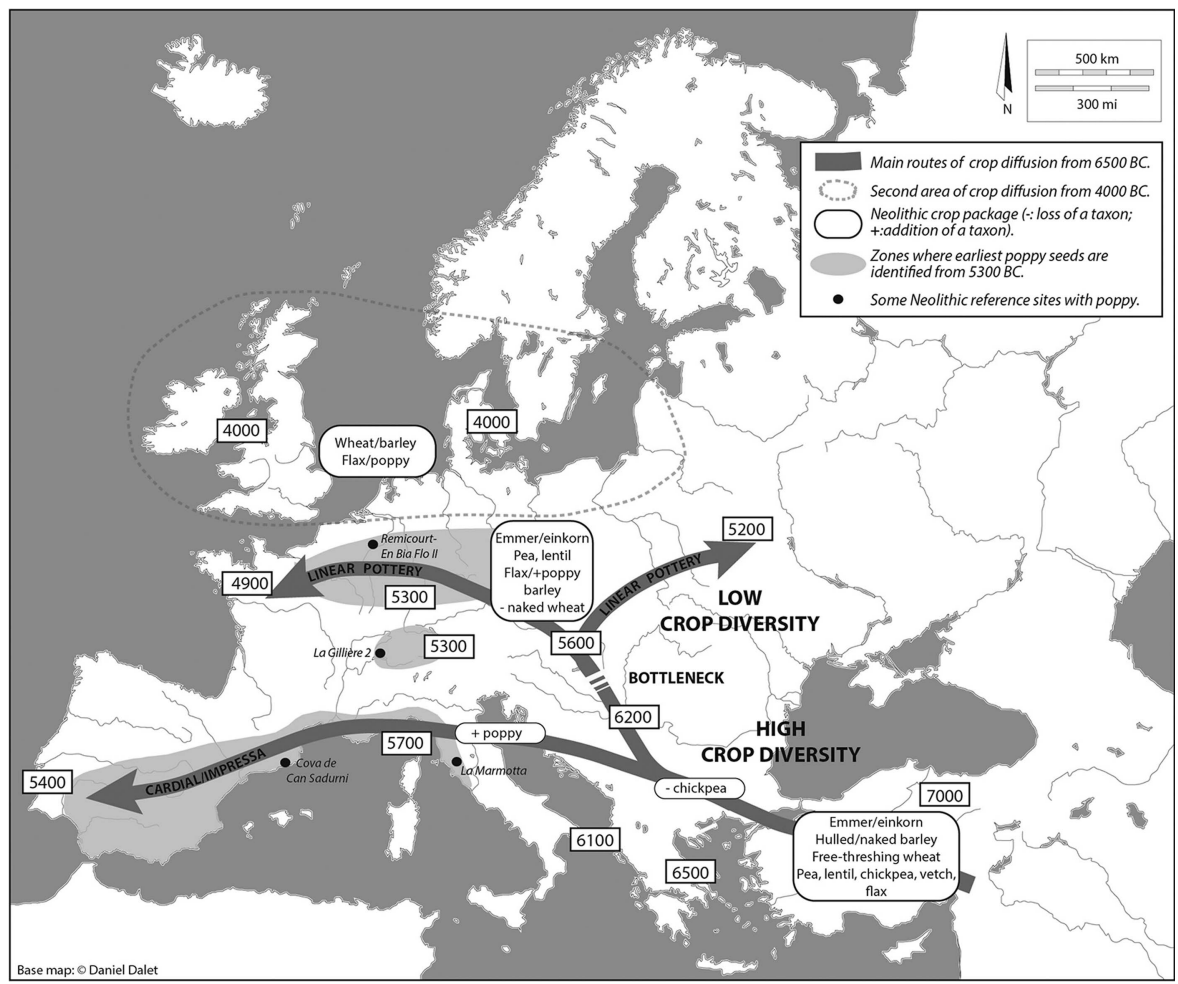

Figure 2. Chronological framework of cultivated plant dispersal during the Neolithic and the first evidence for the opium poppy in Western Europe (modified from Salavert 2017).

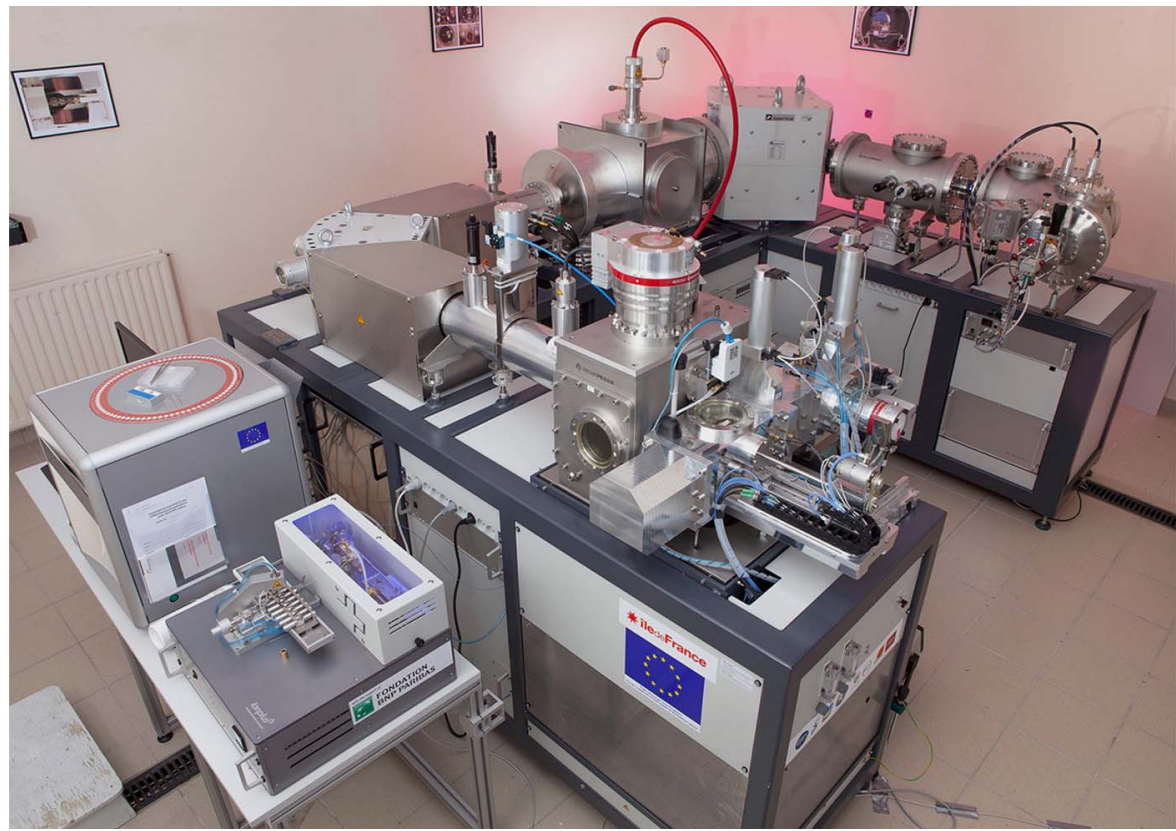

Figure 3. ECHo-MICADAS, the mini radiocarbon dating system at Gif-sur-Yvette, France (photograph: F. Rhodes/CEA).

(C) Antiquity Publications Ltd, 2018 


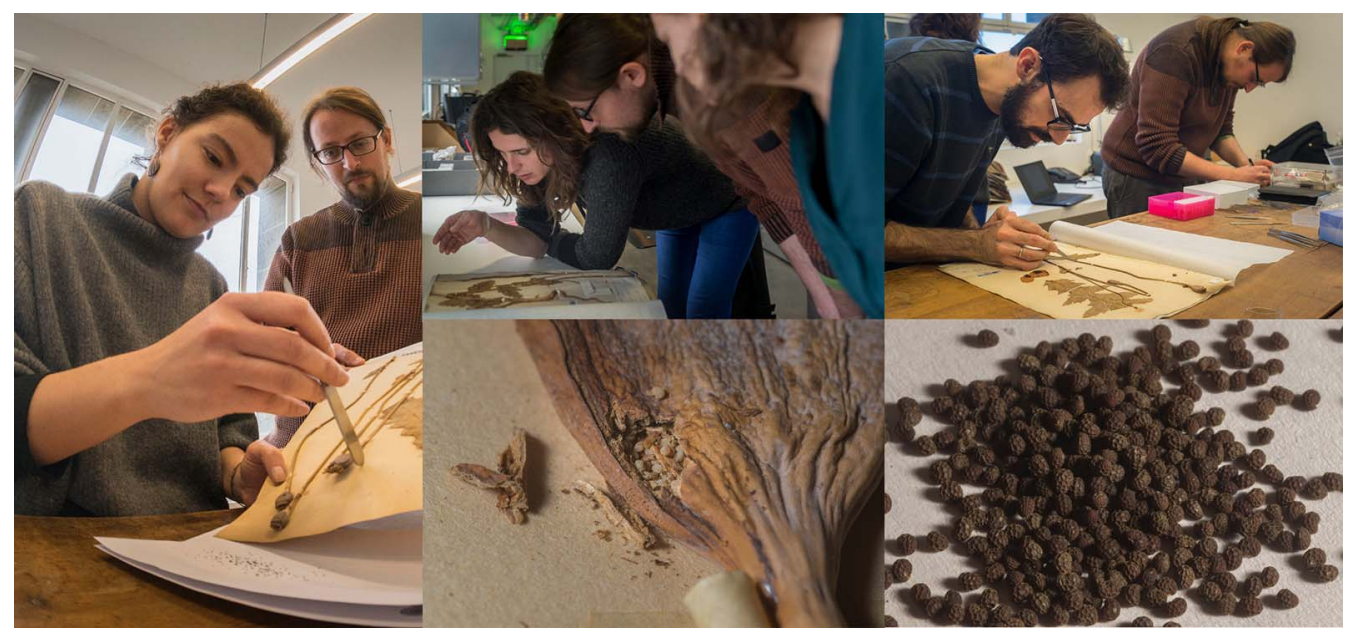

Figure 4. Sampling of seeds from historical specimens of Papaver somniferum at the Herbier national of the Muséum national d'Histoire naturelle in Paris for morphometric-geometric analysis (photograph: R. Soteras).

be analysed using a geographic information system (open-source software, QGIS ${ }^{\odot}$ ), in order to identify the potential cradle(s), rhythms and diffusion processes of the opium poppy in Neolithic Western Europe. The project also aims to create a European interdisciplinary network to study the history of the opium poppy over a longer period of time and larger geographic area (Figure 4).

\section{Acknowledgements}

This project 'Origine et premières diffusions du pavot somnifere en Europe au Néolithique' has received a research grant from the Fyssen Foundation. We would like to thank the following colleagues for their helpful advice and for providing seeds to the radiocarbon programme: C. Bakels, A. Bienek, N. Bleicher, E. Bonnaire, L. Bouby, C. Bouchaud, C. Brombacher, L. Castelletti, P.-A. Chouvy, I. Vostrovska, F. Jabbour, P. Marinval, R. Nisbet, M. Rottoli, N. Rovira, A. Schlumbaum, F. Toulemonde, O. Tombret, A. de Vareilles-Sommières, A. Jesus, R. Soteras and A. Fortó. We also acknowledge the GDRE Bioarch and the SNSF Professorship funding (PP00P1_170515) for the biometric analyses of poppy seeds (coordination: F. Antolín).

\section{References}

Antolín, F., S. Jacomet \& R. Buxó. 2015. The hard knock life. Archaeobotanical data on farming practices during the Neolithic (5400$2300 \mathrm{cal} \mathrm{BC}$ ) in the NE of the Iberian Peninsula. Journal of Archaeological Science 61: 90-104. https://doi.org/10.1016/j.jas.2015.05.007

BaKels, C.C. 1996. Fruits and seeds from the Linearbandkeramik settlement at Meindling, Germany, with special reference to Papaver somniferum. Analecta Praehistorica Leidensia 25: 55-68.

Hammer, K. \& R. Fritsch. 1979. Zur

Frage nach der Ursprungsart des

(C) Antiquity Publications Ltd, 2018
Kulturmohns (Papaver somniferum L.). Kulturpflanze XXV: 113-24. https://doi.org/10.1007/BF02014808

Kritikos, P.G. \& S.P. Papadaki. 1967. The history of the poppy and of opium and their expansion in antiquity in the Eastern Mediterranean area. Bulletin of Narcotics 19: 17-38.

Martin, L. 2015. Plant economy and territory exploitation in the Alps during the Neolithic (5000-4200 cal BC): first results of archaeobotanical studies in the Valais (Switzerland). Vegetation History and Archaeobotany 24: 63-73. https://doi.org/10.1007/s00334-014-0490-y 
Salavert, A. 2010. Le pavot (Papaver somniferum) à la fin du Ge millénaire av. J.-C. en Europe occidentale. Anthropobotanica 1: 3-16.

- 2011. Plant economy of the first farmers of central Belgium (Linearbandkeramik, 5200-5000 BC).

Vegetation History and Archaeobotany 20:

321-32. https://doi.org/10.1007/s00334011-0297-z
- 2017. Agricultural dispersals in Mediterranean and temperate Europe. Oxford Research Encyclopedia of Environmental Science. https://doi.org/ 10.1093/acrefore/9780199389414.013.307

Schultze-Motel, J. 1979. The prehistoric remains of the opium poppy (P. somniferum) and the theory of the species. Kulturplanze 27: 207-16. https://doi.org/10.1007/BF02014651 